\title{
Maternal Health Care Expenditure among Women in Rural Areas of Pakistan
}

\author{
Abdul-ur-Rehman, ${ }^{1}$ Muhammad Adnan, ${ }^{2}$ Hina Mahmood, ${ }^{3}$ Mahmoodul Hassan, ${ }^{4}$ Ayesha Humayun ${ }^{5}$
}

\section{Abstract}

Background: With Pakistan failing to achieve Millennium Development Goals we have now entered into a new era of Sustainable Development Goals. Decreasing child mortality, improving maternal health and increasing the proportion of births by trained birth attendants, are the areas with unmet goals. As $29.5 \%$ of population of Pakistan is below the poverty line, expenditure on maternal health care services is of great importance as it determines the utilization of health care services to a large extent.

Objective: To assess maternal health care expenditure and its sociodemographic predictors in rural Khanewal, Punjab, Pakistan.

Methodology: In this cross sectional study average cost on delivery (both SVD and Cesarean section) was assessed in both public and private sector of rural

\footnotetext{
${ }^{1}$ Medical Officer BHU 55/10R, Tehsil Jahanian, District Khanewal, Pakistan

${ }^{2}$ Medical Officer Neurosurgery ward, DHQ teaching hospital, D G Khan, Pakistan

${ }^{3}$ Department of Public Health and Community Medicine, SKZMDC, Lahore, Pakistan

${ }^{4}$ PG Trainee Medicine, Nishtar Hospital, Multan

${ }^{5}$ Department of Public Health and Community Medicine, SKZMDC, Lahore, Pakistan
}

Date of Submission: 20-03-2017

Date of $1^{\text {st }}$ Revision Received: 22-05-2017

Date of Acceptance for Publication: 26-05-2017

Conflict of Interest: None

Funding Source: None

\section{Contribution}

All Authors have contributed in Study Design, Data Collection, Data Analysis, Data Interpretation, Manuscript Writing and Approval.
Khanewal. Total 257 women who had delivered in the last one year were included.

Results: Results revealed that $69.3 \%$ of mothers were illiterate.56.8\% sought antenatal care in public health unit and $43.2 \%$ in a private health care facility. $49.8 \%$ delivered in a public health unit and $50.2 \%$ in private health care facility. Total expense on antenatal care and delivery was found to be $<4,000 \mathrm{PKR}(<38.16)$ in $55.6 \%$ (reportedly in a public health care unit) and was $>16,000$ PKR (> \$152.65) in $23.3 \%$ (reportedly in a private health care facility). A significant difference was found between expense, in public vs private sector and SVD vs. C-section.

Conclusion: This study revealed that there is high financial cost on maternal health services in both public and private sector of rural Khanewal. Although in private sector the cost is more as compared to public sector but still it is high keeping the notion of free health care services in Pakistan by the government. Therefore it is suggested to improve the quality of health care in public sector and if possible to provide free of cost services to mothers during delivery.

Key words: Maternal health care expenditure, public and private sector, rural area.

\section{Introduction}

During maternity, mothers need continuum of care to ensure that their pregnancy, birth and postnatal period remains free of any complication for best possible health outcomes for themselves and also for their newborns. ${ }^{1}$ There are approx.500,000 maternal deaths each year worldwide,most of which are in rural areas of developing countries including Pakistan. ${ }^{2}$ Risk of a woman dying during pregnancy and child birth is about 1 in 6 in poorest parts of the world. ${ }^{3}$ Maternal 
mortality rate is highest for Asia including Pakistan. ${ }^{2}$ Most maternal deaths are clustered around the period of labour, delivery and in immediate postpartum period. ${ }^{3}$ In Pakistan utilization of health care services i.e., public or private is usually dependent on the socio-demographic factors, level of education, economic factors, cultural beliefs, status of women in the society, gender discrimination, political environment etc. ${ }^{4}$ Health care system itself is also a major determinant. ${ }^{4}$ With WHO recommending every country to spend at least $5 \%$ of GDP on health, Pakistan has managed to raise it to $3.5 \%$ with government contributing only $0.5 \%$ and rest by the private sector i.e., approximately $2.5 \% .^{5}$ Cost of maternity care can be a barrier in accessing a health care unit which may result in increased maternal or neonatal deaths. ${ }^{6}$ Poverty gap and severity of poverty has increased in rural as well as urban areas thus concluding that poverty in Pakistan is a major issue. ${ }^{7}$ The current study high-lights the impact of financial burden in maternal health care services in rural areas of Pakistan and emphasizes the need of effective health reforms to ensure timely, safe and free obstetric facilities for the poor.

The objective of this studyis to assess maternal health care expenditure in rural Khanewal, Pun-jab, Pakistan.

\section{Methods}

This is across sectional study conducted in Chak $56 / 10$ $\mathrm{R}$ having population of about 2,400 and Chak $57 / 10 \mathrm{R}$ having population of about 2,500 in Khanewal district, Punjab, Pakistan. With population of approx.5,000 in both these areas, estimated proportion of $50 \%$ and confidence level of $90 \%$ sample size was calculated using epi info version 7 which came out to be 257 . $10 \%$ was added for the possibility of non-response so the sample size came out to be 283. Mothers who had delivered either by SVD or Cesarean section in the last 1 year were our study population and these eligible females were identified and included in the study through consecutive sampling until the sample size was complete. A structured, self-constructed questionnaire was administered after taking verbal informed consent.Questionnaire was pre-tested on subjects not part of the study. Cronbach alpha came out to be 0.8 showing that questionnaire was valid.257 complete questionnaires were entered and data was analysed on SPSS version 21. Client data recorded was kept anonymous and all other ethical concerns were addressed keeping in view the ethical guidelines of Helsinki's declaration.

\section{Results}

Monthly income was categorized showing that majority i.e., $32.3 \%$ of the families had income ranging between 5,000PKR (\$47.7)-10,000PKR (\$95.41). Occupation of head of family was asked which revealed that $46.3 \%$ of the people were labourers, $22.6 \%$ were doing private jobs, $20.6 \%$ were government servants, $5.4 \%$ were farmers, $2.7 \%$ were businessmen and $2.3 \%$ were land owners. The results also showed that $69.3 \%$ of the mothers were illiterate and only $30.7 \%$ were literate (Table 1). Antenatal care was sought in a public unit by $56.8 \%$ of mothers and by $43.2 \%$ in a private health care facility.69.6\% of mothers delivered had SVD and $30.4 \%$ had C-section. $49.8 \%$ of mothers delivered in a public unit and $50.2 \%$ in private sector. Total expense of delivery was reported to be less $<4,000$ PKR $(<\$ 38.16)$ in $55.6 \%$ of mothers and was $>16,000$ PKR $(>\$ 152.65)$ in $23.3 \%$ with the rest lying in between (Table 2). Expense in relation to antenatal and natal care variables was calculated which showed that public sector provided cheaper antenatal care as compared to private sector. In majority of mothers who had SVD the expense was less than 8000 PKR (\$76.32)as compared to mothers who had Csection, in whom it was $>16000$ PKR (\$152.65). Delivery as observed was cheaper in public health care unit as compared to private health care facility. A significant difference was found between expense, in public vs. private sector and SVD vs. C-section (Table 3).

Table 1: Distribution of Socio-demographic Factors.

\begin{tabular}{|l|c|c|c|}
\hline \multicolumn{1}{|c|}{ Socio-demographic Factors } & Frequency $\mathbf{N}=\mathbf{2 5 7}$ & Percent \% & Cumulative Percent \% \\
\hline Income: & & & \\
\hline $1-5,000 P K R(\$ 0.01-47.7)$ & 37 & 14.4 & 14.4 \\
\hline $5,000-10,000 P K R(\$ 47.7-95.41)$ & 83 & 32.3 & 46.7 \\
\hline
\end{tabular}




\begin{tabular}{|l|r|r|r|}
\hline $10,000-15,000 P K R(\$ 95.41-143.11)$ & 61 & 23.7 & 70.4 \\
\hline $15,000-20,000$ PR $(\$ 143.11-190.81)$ & 18 & 7.0 & 77.4 \\
\hline Above 20,000(more than \$190.81) & 58 & 22.6 & 100.0 \\
\hline Occupation: & \multicolumn{3}{|l|}{} \\
\hline Laborer & 119 & 46.3 & 46.3 \\
\hline Farmer & 14 & 5.4 & 51.8 \\
\hline Land Owner & 6 & 2.3 & 54.1 \\
\hline Government Servant & 53 & 2.6 & 74.7 \\
\hline Business Man & 7 & 22.6 & 77.4 \\
\hline Private Servant & 58 & & 100.0 \\
\hline Educational Qualification of Mother: & & 69.3 & 69.3 \\
\hline Illiterate & 178 & 20.6 & 89.9 \\
\hline Primary & 53 & 7.4 & 97.3 \\
\hline Secondary & 19 & 1.2 & 98.4 \\
\hline Higher Secondary & 3 & 1.6 & 100.0 \\
\hline Graduate or above & 4 & & \\
\hline
\end{tabular}

Table 2: Antenatal Care and Expenses on Delivery.

\begin{tabular}{|l|c|c|c|}
\hline \multicolumn{1}{|c|}{ Items } & Frequency & Percent\% & Cumulative Percent\% \\
\hline Place of Antenatal Care: & & & \\
\hline Public & 146 & 56.8 & 100.0 \\
\hline Private & 111 & 43.2 & \\
\hline Mode of Delivery: & & & 69.6 \\
\hline SVD & 179 & 69.6 & 100.0 \\
\hline C-sec & 78 & 30.4 & \\
\hline Place of Delivery: & & & 49.8 \\
\hline Public & 128 & 49.8 & 100.0 \\
\hline Private & 129 & 50.2 & \\
\hline Total Expense: & & & 55.6 \\
\hline $1-4,000$ PKR $(\$ 0.01-38.16)$ & 143 & 55.6 & 75.8 \\
\hline $4,000-8,000 P K R(\$ 38.16-76.32)$ & 34 & 13.2 & 76.6 \\
\hline $8,000-12,000 P K R(\$ 76.32-114.49)$ & 16 & 6.2 & 100.0 \\
\hline $12,000-16,000 P K R(\$ 114.49-152.65)$ & 4 & 1.6 & \\
\hline Above 16,000PKR(above \$152.65) & 60 & 23.4 & \\
\hline
\end{tabular}


Table 3: Expense in Relation to Antenatal and Natal Care Variables.

\begin{tabular}{|c|c|c|c|c|}
\hline Items & $\begin{array}{l}<\text { 8,000PKR/ } \\
\text { Expense }\end{array}$ & $\begin{array}{c}\text { 8,000-16000PKR/ } \\
\text { Expense }\end{array}$ & $\begin{array}{l}>16000 \mathrm{PKR} / \\
\text { Expense }\end{array}$ & P-value \\
\hline \multicolumn{5}{|c|}{ Place of Antenatal Care: } \\
\hline Public & 128 & 5 & 13 & $<0.001$ \\
\hline Private & 49 & 15 & 47 & \\
\hline \multicolumn{5}{|c|}{ Mode of Delivery: } \\
\hline SVD & 158 & 14 & 7 & $<0.001$ \\
\hline C-sec & 19 & 6 & 53 & \\
\hline \multicolumn{5}{|c|}{ Place of Delivery: } \\
\hline Public & 123 & 1 & 4 & $<0.001$ \\
\hline Private & 54 & 19 & 56 & \\
\hline Total & 531 & 60 & 180 & \\
\hline
\end{tabular}

\section{Discussion}

Poverty as in other developing countries is a core issue in Pakistan. ${ }^{8}$ A study done on low-middle income countries of Asia showed that health care payments exacerbate poverty. As reported $>60 \%$ of health care costs are paid out of pocket by households. Number of Asians living below $\$ 1 /$ day can be reduced by reducing such out of pocket health payments. ${ }^{9}$ Education is one of the predictor in utilization of health care facility at individual level whereas socioeconomic status is a significant predictor at house hold level. ${ }^{10}$ Cost can be a major issue in seeking alternate maternity health care. ${ }^{11}$ Another study done in Pakistan showed that low literacy rate of mothers and low socioeconomic status may contribute to poor utilization of primary health care services. ${ }^{12}$ This study showed that literacy rate was $30.7 \%$ among mothers which is in line with literacy rate of women in rural areas of Pakistan i.e., $25 \% .{ }^{13}$ Our study revealed that total expense was on extremes in public as compared to private health care facility i.e., cost was $<4,000 \mathrm{PKR}(\$ 38.16)$ in a public heath care unit and was $>16,000 \mathrm{PKR}(\$ 152.65)$ in a private health care facility as reported by mothers. Private health care facility was considered more reliable but was more expensive as reported. It is seen that health care expenditures can exacerbate poverty of a household. ${ }^{14}$ In our study significant difference was seenbetween expense in public vs private sector, SVD vs C-section, which shows health care is expensive in private sector as compared to private sector.In contrast to other countries where public sector is considered more reliable, ${ }^{15}$ in Pakistan the use of private health facility increases with increasing maternal education and socio-economic status of the family. ${ }^{16}$ With minimum suggested rate of $<5 \%$ for $\mathrm{C}$-section by $\mathrm{WHO},{ }^{17}$ the rates are rising alarmingly worldwide with its determinants being controversial in lower- middle income countries. ${ }^{18}$ Our study also showed that rate of C-section in private sector is moreas compared to mothers in public sector, though WHO recommends 5 to $15 \%$ C.Sec rate for a comprehensive Emergency Obstetric Care facility. This raises questions about the efficacy of private sector hospitals and its client-centeredness.

Our study also have some limitations for e.g. it is relied totally upon respondent's recall and only one district of Punjab was selected, so caution is needed in generalizing the results.

\section{Conclusion}

The present study revealed high financial cost on maternal health both in public and private health care facilities in rural Khanewal. Although private sector cost is more but public sector cost is also high keeping in view, the notion of free health care services raised by Governments in Pakistan. Place of antenatal care, place of delivery and mode of delivery is significantly associated with income level .It is suggested that alternative financing mechanisms may be used in public sector health system to improve its utilization by community. 


\section{References}

1. Safer MP. Making pregnancy safer: the critical role of the skilled attendant. World Health Organ: Geneva. 2004.

2. Abou Zahr C, Royston E. Maternal mortality: a global factbook. 1991.

3. Ronsmans C, Graham WJ, group LMSSs. Maternal mortality: who, when, where, and why. Lancet. 2006; 368 (9542):1189-200.

4. Shaikh BT, Hatcher J. Health seeking behaviour and health service utilization in Pakistan: challenging the policy makers. J Public Health. 2005;27(1):49-54.

5. Ahmed J, Shaikh BT. An all time low budget for healthcare in Pakistan. JColl Physicians Surg Pak. 2008;18 (6):388.

6. Skordis-Worrall J, Pace N, Bapat U, Das S, More NS, Joshi W, et al. Maternal and neonatal health expenditure in Mumbai slums (India): a cross sectional study. BMC Public Health. 2011;11(1):150.

7. Nazli H, Meilke K. Implications of high food prices for poverty in Pakistan. Agric Econ. 2008;39(1):477-84.

8. Anwar T, Qureshi SK. Trends in absolute poverty in Pakistan: 1990-91 and 2001. Pak Dev Rev. 2002;85978.

9. Van Doorslaer E, O'Donnell O, Rannan-Eliya RP, Somanathan A, Adhikari SR, Garg CC, et al. Effect of payments for health care on poverty estimates in 11 countries in Asia: an analysis of household survey data. Lancet. 2006;368 (9544):1357-64.

10. Babalola S, Fatusi A. Determinants of use of maternal health services in Nigeria-looking beyond individual and household factors. BMC Pregnancy Childbirth. 2009;9(1):43.

11. Khan A, Zaman S. Costs of vaginal delivery and Caesarean section at a tertiary level public hospital in Islamabad, Pakistan. BMC Pregnancy Childbirth. 2010;10 (1):2.

12. Khowaja K. Healthcare systems and care delivery in Pakistan. JNurs Adm. 2009;39(6):263-5.

13. Latif A. A critical analysis of school enrollment and literacy rates of girls and women in Pakistan. Educ Stud. 2009;45(5):424-39.

14. Balarajan Y, Selvaraj S, Subramanian S. Health care and equity in India. Lancet. 2011;377(9764):505-15.

15. Brodribb W, Zadoroznyj M, Nesic M, Kruske S, Miller YD. Beyond the hospital door: a retrospective, cohort study of associations between birthing in the public or private sector and women's postpartum care. BMC Health Serv Res. 2015;15(1):14.

16. Khan REA, Noreen S. Household Choice of Public versus Private Health Institution for Maternal Health-Care: A Case Study of Bahawalpur (Pakistan). Pak J Commer Soc Sci. 2016;10(3):444-60.

17. Ray A, Vadvagi N. Assessment and comparison of Caesarean section rates to WHO recommendations. The Online Journal of Clinical Audits. 2015;7(4).

18. Vogel JP, Betrán AP, Vindevoghel N, Souza JP, Torloni MR, Zhang J, et al. Use of the Robson classification to assess caesarean section trends in 21 countries: a secondary analysis of two WHO multicountry surveys. Lancet Glob Health. 2015;3(5):260-70. 